\title{
O FRACASSO DAS POLÍTICAS HABITACIONAIS E A EXCLUSÃO SOCIAL: OS EXCLUÍDOS DA CIDADE SOB OS OLHARES DE ALOÍSIO AZEVEDO, DARCY RIBEIRO E PEDRO DEMO
}

\author{
Cláudia Karina Ladeia Batista ${ }^{1}$ \\ Debora Markman ${ }^{2}$
}

BATISTA, C. K. L.; MARKMAN, D. O fracasso das políticas habitacionais e a exclusão social: os excluídos da cidade sob os olhares de Aloísio Azevedo, Darcy Ribeiro e Pedro Demo. Rev. Ciênc. Juríd. Soc. UNIPAR. Umuarama. v. 21, n. 2, p. 169-183, jul./dez. 2018.

RESUMO: O objetivo do presente trabalho é, por intermédio de pesquisa bibliográfica e documental, de caráter qualitativo, estudar, a partir de Aloísio Azevedo, Darcy Ribeiro e Pedro Demo, a questão da exclusão social provocada pelo insucesso das políticas habitacionais urbanas. O presente trabalho foi dividido em três partes. Na primeira, foi estudada a crise habitacional no Brasil. A seguir, tratou-se do adensamento urbano provocado pela abolição da escravatura. $\mathrm{Na}$ sequência, tratou-se da exclusão provocada pelo fracasso das políticas habitacionais. Na escrita, foi utilizado o procedimento dedutivo. Justifica-se o presente trabalho, em decorrência da necessidade de se observar e tratar o problema da exclusão, em todos os seus aspectos, especialmente no que concerne ao direito à moradia.

PALAVRAS-CHAVE: Alísio Azevedo; Darcy Ribeiro; Exclusão Social; Insucesso das Políticas Habitacionais; Pedro Demo.

\section{THE FAILURE OF HOUSING POLICIES AND SOCIAL EXCLUSION: THE EXCLUDED PEOPLE OF THE CITY IN THE EYES OF ALOISIO AZEVEDO, DARCY RIBEIRO, AND PEDRO DEMO}

\begin{abstract}
The authors intend to study, through a qualitative literature and document review based on the works of Aloísio Azevedo, Darcy Ribeiro and Pedro Demo, the issue of social exclusion caused by the failure of urban housing

DOI: $10.25110 /$ rcjs.v21i2.2018.7500

${ }^{1}$ Doutora em Direito pela Faculdade de Direito de Bauru (CEUB-ITE). Mestre em Direito. Especialista em Direito Civil e Processual Civil. Professora Adjunta da Universidade Estadual de Mato Grosso do Sul (UEMS), Unidade Universitária de Paranaíba-MS. E-mail: <claudiabatista@uems.br>.

${ }^{2}$ Bacharel em Direito pela Universidade Presbiteriana Mackenzie. Especialista em Direito do Trabalho, Direito Constitucional e Direito Previdenciário. Mestranda em Direito pela Universidade Metodista de Piracicaba - UNIMEP. Autora da obra: "A Manifestação do Fenômeno Assédio Moral nas Relações de Emprego”, publicada pela Editora CRV. < deboramark@icloud.com>.
\end{abstract}


policies. This paper was divided into three parts. The first part addressed the housing crisis in Brazil. Then, it studied the urban densification caused by the abolition of slavery. This was followed by the exclusion caused by the failure of housing policies. It used a deductive procedure for its developing, justified by the need to observe and address the issue of exclusion in all its aspects, especially in relation to the right to housing.

KEYWORDS: Alísio Azevedo; Darcy Ribeiro; Failure of Housing Policies; Pedro Demo; Social exclusion.

\section{EL FRACASO DE LAS POLÍTICAS HABITACIONALES Y LA EXCLUSIÓN SOCIAL: LOS EXCLUÍDOS DE LA CIUDAD BAJO LAS MIRADAS DE ALOÍSIO AZEVEDO, DARCY RIBEIRO Y PEDRO DEMO}

RESEUMEN: El objetivo de este artículo es, por intermedio de investigación bibliográfica y documental, de carácter cualitativo, estudiar, a partir de Aloísio Azevedo, Darcy Ribeiro y Pedro Demo, la cuestión de la exclusión social provocada por el fracaso de las políticas habitacionales urbanas. La investigación ha sido dividida en tres partes. En la primera, se estudió la crisis habitacional en Brasil, A seguir, se trató de la densificación urbana provocada por la abolición de la esclavatura. Enseguida, se ha tratado de la exclusión provocada por el fracaso de las políticas habitacionales. En la escrita se ha utilizado el procedimiento deductivo. Se justifica el presente estudio, en recurrencia de la necesidad de observar y tratar el problema de la exclusión, en todos sus aspectos, especialmente en lo que concierne al derecho a la vivienda.

PALABRAS CLAVE: Aloísio Azevedo; Darcy Ribeiro; Exclusión Social; Fracaso de las Políticas Habitacionales; Pedro Demo.

\section{INTRODUÇÃO}

O objetivo do presente trabalho é, por intermédio de pesquisa bibliográfica e documental, de caráter qualitativo, estudar, a partir de Aloísio Azevedo, Darcy Ribeiro e Pedro Demo, a questão da exclusão social provocada pelo insucesso das políticas habitacionais urbanas.

O presente trabalho foi dividido em três partes. Na primeira, foi estudada a crise habitacional no Brasil. A seguir, tratou-se do adensamento urbano provocado pela abolição da escravatura. Na sequência, tratou-se da exclusão provocada pelo fracasso das políticas habitacionais.

$\mathrm{Na}$ escrita, foi utilizado o procedimento dedutivo. Justifica-se o presente trabalho, em decorrência da necessidade de se observar e tratar o problema da 
exclusão, em todos os seus aspectos, especialmente no que concerne ao direito à moradia.

\section{A CRISE HABITACIONAL E O DIREITO FUNDAMENTAL À MORA- DIA}

A crise de moradia no Brasil não é algo recente. A intensificação da ocupação urbana desordenada surgiu, especialmente, com a abolição da escravatura, passando pela mecanização no campo e pela industrialização nos grandes centros. Esse conjunto de fatores resultou em um processo de êxodo rural acentuado, produzindo a escassez de moradia

O crescimento dos centros urbanos afeta, há muito, várias grandes cidades em todo o mundo. A especulação imobiliária, por exemplo, inflacionou o custo de morar nas regiões mais centralizadas, realocando na periferia os que a condição financeira não lhes permitiu permanecer. Frederich Engels, (1984, p. 45) já retratava, tais problemas:

A expansão das grandes cidades modernas dá um valor artificial, colossalmente aumentado, ao solo em certas áreas, particularmente nas de localização central; os edifícios nelas construídos, em vez de aumentarem esse valor, fazem- no antes descer, pois já não correspondem às condições alteradas; são demolidos e substituídos por outros. Isto acontece antes de tudo com habitações operárias localizadas no centro, cujos alugueres nunca ou então só com extrema lentidão ultrapassam um certo máximo, mesmo que as casas estejam superpovoadas em extremo. Elas são demolidas e em seu lugar constroem-se lojas, armazéns, edifícios públicos. [...] O resultado é que os operários vão sendo empurrados do centro das cidades para os arredores, que as habitações operárias e as habitações pequenas em geral se vão tornando raras e caras e muitas vezes é mesmo impossível encontrá-las, pois nestas condições a indústria da construção, à qual as habitações mais caras oferecem um campo de especulação muito melhor, só excepcionalmente construirá habitações operárias. (ENGELS,1984, p. 45)

Demonstra-se, assim, que os problemas de insuficiência de habitações no Brasil, de marginalização dos trabalhadores pela especulação imobiliária e valorização dos grandes centros há muito também afligem os países europeus, cujo desenvolvimento social e econômico, apesar dos entraves da guerra, está em 
um estágio mais avançado.

No Brasil, muitas são as questões associadas à localização geográfica periférica: a distância das oportunidades de emprego e serviços essenciais, a demanda por transporte público, o tempo e o custo em deslocamento, a falta de acesso à escolas e serviços de saúde, entre outros. Nesse sentido, Loreci Nolasco (2008, p. 88) informa:

Se em seu estado natural o homem, na imensidão do orbe, encontrava um ponto para estabelecer-se e a abundância de material para a sua edificação, o incremento da população e a carência de espaços livres foram comprimindo a potencialidade de exercício de moradia, até a sua gradual e drástica redução, senão extinção para os mais desfavorecidos (os moradores debaixo das pontes, das ruas, das praças e das calçadas), como ocorre diariamente nos grandes aglomerados humanos.

Há outros fatores também permeiam essa deficiência, como as ocupações irregulares, quase sempre desprovidas de infraestrutura e serviços públicos, constituindo óbice ao exercício do direito de bem morar. Tratando da exclusão social e marginalização, a literatura nacional contempla várias obras sobre o que, à época, já se vislumbrava ser um grave problema social.

\section{O FIM DA ESCRAVATURA E A EXPANSÃO DA POPULAÇÃO URBA- NA: DA SENZALA AO CORTIÇO}

A história do crescimento urbano e do adensamento populacional na periferia dos grandes centros têm estreita ligação com o fim da escravatura. A desocupação das senzalas desalojou um contingente populacional desprovido de qualquer amparo. O exercício do morar passou a ser realizado de forma precária.

$\mathrm{Na}$ descrição do cortiço feita no homônimo romance de Aluísio de Azevedo $^{3}$ implicava em verdadeiro estereótipo dos habitantes do lugar. Regina Dalcastagnè (2001) defende que, embora estereotipadas, as personagens que transitam cortiço e nele habitam contam a história do protagonista anti-herói

\footnotetext{
${ }^{3}$ Ícone da literatura pátria, O Cortiço, de Aluísio Azevedo, retrata de forma crua, por vezes cruel, a realidade dos mecanismos sociais de dominação e exploração do homem pelo homem. O romance retrata as discrepâncias na sociedade carioca do século XIX, sobretudo por meio da abordagem de um tema periférico, mas que na obra ganha tamanha importância que chega da lhe dar o título. Os problemas e crises enfrentados pelos personagens estão, em sua maioria, relacionados com a precariedade do local em que a trama se passa. Retratando por via oblíqua os conflitos intersociais e inter-raciais, a obra deixa nas entrelinhas a ideia de descrença, quando o cortiço incendiado dá lugar a uma avenida, empurrando os moradores para margem.
} 
João Romão, que enriqueceu explorando a miséria alheia.

É por meio de personagens pouco românticos, expostos a uma dura realidade, em sua maioria, paupérrimos e marginalizados, que o autor tece a trama com o objetivo de servir de pano de fundo para a saga de João Romão. O locador das unidades do cortiço pretende pertencer à elite carioca (e de fato consegue, por meios pouco ortodoxos). De acordo com Ramos (2006, p. 556):

João Romão buscava apenas o lucro com seu investimento, pouco se preocupando com as condições a que seus inquilinos estavam se sujeitando, como abaixo se verá, essa prática se mantém até os atuais dias através da utilização desviada de políticas públicas que deveriam buscar suprir o déficit habitacional da maioria da população carente e que acaba por não ser contemplada, remanescendo o status de indignidade a que esta parcela da população está sujeita. Esse retrato brasileiro sobre as condições das moradias daquele período, apesar de consideráveis avanços, ainda hoje, quase 28 anos da promulgação da Constituição Cidadã, não logrou alcançar as promessas contidas no Art. $3^{\circ}$ e seus incisos, dentre outras normas contidas de forma esparsa no seu corpo.

Azevedo se vale da personagem para expor o fato de que a elite não existe sozinha - existe em relação aos desfavorecidos. No romance ' $\mathrm{O}$ cortiço' é retratado como verdadeiro antro que abriga despossuídos, prostitutas, bêbados, lavadeiras e "capoeiras", expressão usada para designar ex-escravos tidos como verdadeiros "foras da lei".

Tratava-se de um local a ser expurgado do convívio da sociedade, quer pela inconveniência de se conviver com seus moradores, segundo expõe a narrativa, quer por realmente apresentar condições pouco salubres e, minimamente, organizadas para o bom exercício do direito de morar.

Mas a realidade dos grandes centros urbanos não destoava do romance de Aluísio Azevedo. A precariedade dos cortiços paulistanos, marcados pela pobreza e ausência de condições salutares mínimas era uma realidade crescente.

$\mathrm{O}$ aparecimento dos primeiros cortiços foi a solução encontrada para acomodar os ex-escravos e trabalhadores que, vindo do campo, "inflavam" cada vez mais os grandes centros, em especial, Rio de Janeiro e São Paulo.

Instalados normalmente em terrenos de pouco valor, geralmente situados nas várzeas, que ficavam inundadas durante as chuvas de verão, os cortiços foram responsáveis pelo adensamento populacional perto dos locais de trabalho, e foi um bom negócio para os empreendedores capitalistas que começavam a se expandir (SCHWAREZ, 1998, p. 38). 
Já em 1890, ano da primeira edição da obra, os aglomerados urbanos representavam um desafio ao Poder Público. Nesse sentido era preciso compreender o destino da República que se encontrava diante de um desafio: alcançar um marco de crescimento nos moldes europeus e dar fim à classe pobre, vista como impedimento pela opulenta minoria (CHALHOUB, p. 17).

A gênese das atuais favelas surgia já contaminada de ideais higienistas, que pregavam a necessidade de dar fim ao que se considerava reduto de moléstias. A favela nasceu na margem da cidade e à margem da cidade, como bem demonstra o autor:

A destruição da Cabeça de Porco marcou o início do fim de uma era, pois dramatizou, como nenhum outro evento, o processo em andamento de erradicação dos cortiços cariocas. Nos dias que se seguiram, o prefeito da Capital Federal foi calorosamente aclamado pela imprensa - ao varrer do mapa aquela "sujeira", ele havia prestado à cidade "serviço inolvidáveis". Com efeito, trata-se de algo inesquecível: nem bem se anunciava o fim da era dos cortiços, e a cidade do Rio já entrava nos séculos das favelas. (CHALHOUB, 1996, p. 19)

O processo caótico de urbanização é bem retratado por Darcy Ribeiro em valoroso estudo sobre a formação social, cultural e política do Brasil, no qual aponta alguns dos fatores que culminaram na desordem dos grandes centros.

Para o autor, a independência derramou milhares de Lusitanos no fim do século XVI, parte deles acolhidos no campo, parte inflando as cidades (RIBEIRO, 1995, p. 193). Nesse mesmo sentido:

A ordem social brasileira, fundada no latifúndio e no direito implícito de ter e manter a terra improdutiva, é tão fervorosamente defendida pela classe política e pelas instituições do governo que isso se torna impraticável. É provável que a União Democrática Ruralista (UDR), que representa os latifundiários no Congresso, seja o mais poderoso órgão do Parlamento. É impensável fazê-la admitir o princípio de que ninguém pode manter a terra improdutiva por força do direito de propriedade, a fim de devolver as terras desaproveitadas à União para programas de colonização (RIBEIRO, 1995, p. 152).

A crise de desemprego na Europa foi grandemente responsável por mandar ao Brasil mais sete (7) milhões de europeus, no final do século XX, fazendo com que o contingente urbanizado passasse de 30,6 milhões em 1920 para 
70,9 milhões em 1960 (RIBEIRO, 1995, p. 207).

$\mathrm{O}$ autor relata ainda que os centros urbanos deram lugar à uma burocracia civil eclesiástica da mais alta hierarquia e a um comércio rico à margem do qual viviam as pessoas em aglomerados urbanos. A par dessa realidade urbana, nos latifúndios seguiam a nobreza aristocrática, cujos filhos estudavam na Europa e passavam alheios aos problemas da urbe.

Assim, apesar das imensas diferenças que mediavam entre as formações socioculturais europeias e brasileiras, ambas eram fruto de um mesmo movimento civilizatório. Com a industrialização se altera essa constelação urbana no que tinha de fundamental, que era sua tecnologia produtiva, transformando todo o seu modo de ser, de pensar e de agir. Provocaria uma sequencia de alterações reflexas nas sociedades dependentes, de natureza tanto técnica quanto ideológica que, aqui também, transfigurara o caráter da própria civilização (RIBEIRO, 1995, p. 149).

Nas palavras do autor, “[...] chegamos à loucura de ter algumas das maiores cidades do mundo, tais como São Paulo e Rio de Janeiro, com o dobro da população de Paris ou Roma, mas dez vezes menos dotadas e serviços urbanos e de oportunidades de trabalho" (RIBEIRO, 1995, p. 198).

$\mathrm{E}$, investigando as raízes da desordem urbana, o autor chega à conclusão de que as monoculturas, a mecanização do campo e, sobretudo, a manutenção da propriedade improdutiva, associada à industrialização dos centros urbanos fizeram com que a imensa massa urbana passasse a ser cada vez maior.

E apresenta o mesmo outro problema, com certa ironia - a crescente massa não poderia ser exportada para a Europa, tal como o inverso foi feito no passado. "Esta massa deve ser reassentada aqui". Mas onde, pergunta-se? (RIBEIRO, 1995, p. 201). Nesse mesmo sentido: O abandono da população urbana pelas autoridades, ou o uso de meios de expulsão, à guisa de limpeza urbana, oprimiu a massa nas morrarias onde nasceram as primeiras favelas, alheias aos regulamentos urbanísticos.

Em São Paulo, favelas se originam 'em chão liso'. Em ambos os casos, sujeitas ao poder paralelo do crime organizado, notadamente do tráfico de drogas, da exploração da prostituição, do jogo do bicho, entre outros. Segundo Ribeiro (1995), os bandos que se instalam no meio das populações faveladas impõem a mais dura opressão, a fim de que impedir que algo lhes escape ao domínio.

É um estado paralelo onde "a escola não ensina, a igreja não catequiza, os partidos não politizam. O que opera é um monstruoso sistema de comunicação de massa fazendo a cabeça das pessoas" (RIBEIRO, 1995, p. 205). 
Na obra intitulada As Américas e a Civilização, Darci Ribeiro aponta que riqueza e pobreza foram, por muito tempo, aceitas como conceitos místicos utilizados para infundir a atitude de resignação que se cristalizou no tempo pelo interesse das classes dominantes. A fervilhante indignação nos estratos subalternos não era capaz de, por si, reordenar a sociedade segundo um projeto próprio viável e progressista. (RIBEIRO, 1988, p. 34-45)

Para Ribeiro (1988), foi fundamental o nascimento da consciência de que o subdesenvolvimento e o atraso eram consequências do desenvolvimento de outros povos, responsáveis pela espoliação dos demais e apropriação dos resultados do processo tecnológico por minorias privilegiadas.

\section{O DESENVOLVIMENTO URBANO E A EXCLUSÃO: OS DADOS, OS PROBLEMAS E A CIDADE}

O desenvolvimento econômico é essencialmente um fenômeno histórico. Enveredando-se no debate acerca do subdesenvimento e das desigualdades, o autor completa seu arquétipo teórico na obra A Fantasia Organizada, na qual relata, quase em desabafo "Vi agora mais nitidamente o considerável peso da herança cultural" (FURTADO, 1985, p 226).

$\mathrm{O}$ autor foi convidado a falar à comissão mista do Congresso Nacional em 1999, cujo objetivo era estudar medidas de combate à pobreza. Em obra intitulada "Em busca de um novo modelo" o autor aponta que à época o Brasil apresentava 53 milhões de pobres, o que correspondia a $34 \%$ da população. Salienta, porém, que em países cuja renda per capta era semelhante à do Brasil (algo em torno de 4500 dólares), os pobres correspondiam a 10\% da população, denotando, pois, que o grande problema do país era a concentração de renda. Tal concentração era tão alarmante que entre os 92 países pesquisados pelo PNUD (Programa das Nações Unidas para o Desenvolvimento), o Brasil só não perdeu para a África do Sul e o Malawi (FURTADO, 2002, p.11-13).

Entre os principais fatores indicativos da pobreza, o autor indicava três deles: a fome endêmica, a questão da habitação popular e a insuficiência de escolaridade. Para o autor, a pobreza não resulta de uma disparidade entre o mundo rural e urbano, como na Índia. Decorre mais da concentração de renda urbana. (FURTADO, 2002, p.15-17)

A escassez de habitação foi um problema enfrentado por diversos países, notadamente no pós-guerra. Furtado relata a experiência da França, que desde os anos 50 investiu na construção de habitações populares, casas e apartamentos de aluguel reduzido, sanando o déficit em pouco mais de 10 anos (FURTADO, 2002, p.18).

No Brasil o autor aponta como um retrocesso o fechamento do Banco 
da Habitação nos anos 80. Aponta que tal medida se deu mais por se tratar de uma instituição impopular (criação do regime militar), que propriamente de sua ineficiência. Furtado (2002, p. 19) é enfático ao retratar que "o déficit habitacional é o grande empecilho para superar-se o quadro de pobreza". E assim arremata o autor:

A pobreza no Brasil não resulta das disparidades entre o mundo rural e o mundo urbano, como na Índia, e sim da concentração de renda urbana. No mundo inteiro houve e há problemas de déficit habitacional. Mas todos os países em que houve e há políticas de financiamento da construção resolveram parcialmente, ou pelo menos evitaram o agravamento do problema. Em alguns países da Europa, e na Nova Zelândia, a habitação é uma meta social definida pelo governo. Desde os anos 1950 a França vem construindo as chamadas habitations à loyer modéré (HLM), casas e apartamentos de aluguel reduzidos; o déficit habitacional que havia no final da Segunda Guerra foi sanado em pouco mais de dez anos. Essa política de financiamento nos tem cruelmente faltado. O Banco da Habitação realizou muita coisa, mas foi fechado em meados dos anos 1980, sem uma crítica mais séria do que estava fazendo. Como era uma herança dos governos militares, havia contra ele uma opinião pública bastante desfavorável. Hoje se percebe que foi um erro ter acabado com esse banco, auxílio indispensável à solução do problema mais grave e de mais difícil solução no Brasil: a habitação. Com efeito, o déficit habitacional é o grande empecilho para superar-se o quadro de pobreza. Os 53 milhões de pobres e miseráveis brasileiros não têm como pagar um aluguel, muito menos como possuir uma moradia. Suprir esse déficit exige um investimento a longo prazo, uma massa de recursos que podemos estimar em $4 \%$ do produto nacional. O constante endividamento do país agrava o quadro da pobreza e complica a implantação de projetos que visem a solucioná-la. Hoje, por exemplo, se o governo conseguisse o equivalente a $4 \%$ do produto nacional, essa parcela seria logo absorvida pelo pagamento de juros. Daí a importância de aumentar a taxa de poupança. É espantoso que com uma renda média alta, de quase cinco mil dólares, o Brasil tenha uma taxa de poupança tão baixa. Se voltássemos aos patamares de 24 , ou até $25 \%$, haveria recursos suficientes - sem precisar recorrer ao endividamento externo - para enfrentar o problema dos investimentos reprodutivos e o 
do atraso na construção civil (FURTADO, 2002, p. 1719).

Como bem apontam os estudos do economista, há uma diferença entre desenvolvimento e modernização: "Houve desenvolvimento? Não: o Brasil não se desenvolveu; modernizou-se. O desenvolvimento só existe quando a população em seu conjunto é beneficiada" (FURTADO, 2002, p. 21).

No mesmo sentido Drucker aponta que a modernização foi um processo altamente seletivo e desigual, no qual a promessa do fim da pobreza viria no início do desenvolvimento. Segundo o autor, na maior parte dos países que passaram por décadas de desenvolvimento (entre os quais a China e a Índia), o fim da miséria não veio tão rapidamente quanto se esperava.

Antes, porém, criou-se uma classe média dotada de poder de consumo. Tais promessas, relata o autor, eram pontos fortes nas candidaturas dos presidentes Truman e Kennedy "onde cada família de trabalhadores teria uma bela casa para morar e um carro para por na garagem"

Para o autor "a eliminação da pobreza vem no fim, e não no começo do desenvolvimento econômico. Numa sociedade moderna a pobreza é muito mais uma condição social do que econômica, como prova a penúria em que um terço dos negros ainda vivem nos Estados Unidos, o pais mais desenvolvido do mundo" (DRUCKER, 1997, p. 120-121).

Ousa-se defender que tal análise, a princípio desconexa com o presente trabalho, mostra-se na verdade bastante oportuna: o rompimento com a desigualdade requer o rompimento com os próprios fatores geradores da desigualdade: a má distribuição de renda e a exploração homem na tópica mais crua e cruel do liberalismo econômico.

O rompimento com a desigualdade supõe a atuação do Estado, atenuando os rigores do capitalismo por meio de atuação concreta. A positivação de direitos sociais tem por escopo dirimir o rigor dos ideais liberais, de maneira que a meritocracia não seja vista como um pressuposto autêntico de desenvolvimento pessoal e social, mas como um mecanismo cuja implementação justa depende de melhor distribuição de oportunidades.

Dworkin trata do estabelecimento de uma condição inicial de igualdade, utilizando da metáfora de cestas distribuídas aos participantes com conteúdo inicial igualitário, de modo que com o passar do tempo, possuir mais ou menos bens na cesta depende das escolhas e habilidades pessoais - daí advém a meritocracia.

Entende-se, entretanto, que tal como já explanado o processo de formação de nossa sociedade sempre contou com uma massa de desfavorecidos explorada por um contingente mínimo de pessoas detentoras de terras e outros meios de produção, de modo que, neste cenário de desigualdade, não se pode 
considerar o mérito individual.

O discurso da meritocracia encampa muitas críticas aos programas assistenciais de acesso à moradia popular, normalmente com o cunho jocoso de assistencialismo. Entende-se que, no cenário posto, tais medidas visam, justamente, a restabelecer o cenário da igualdade inicial proposta por Dworkin ${ }^{4}$.

Minorando as desigualdades sociais habitualmente marcantes nos países em desenvolvimento por meio do desenvolvimento de políticas públicas de acesso à moradia popular é possível que em algumas décadas o déficit habitacional possa ser reduzido.

Verificou-se que as políticas de regularização urbana tiveram, em sua maioria, caráter higienista. Ao longo dos séculos as políticas habitacionais destinaram-se mais a esconder, camuflar ou retirar a miséria do alcance dos olhos do que propriamente combatê-la. Como bem relata Pedro Demo, a sociedade tende a criar guetos, por meio de políticas sociais fragmentárias, voltadas para uma concepção de bairro, de grupo, de etnia (DEMO, 1998, p. 15).

Para o sociólogo, os indivíduos excluídos podem se sentir desmoralizados, quer por terem perdido a inserção laboral ou residencial, quer por serem assistidos. Não há, porém, “[...] qualquer coisa similar a um movimento mazoquista de auto-exclusão. O próprio sentimento de impotência não poderia confundir-se com a desistência definitiva de reagir" (DEMO, 1998, p. 16).

As políticas de bairro tendem a isolar o homem e torná-lo ainda mais fraco diante do mercado. Assim, as underclass acabam por, na visão de Demo, aprisionar os "pobres do gueto" num contexto injusto e moralista, forçando-os a se integrar-se via trabalho para que não se acomodem sob a assistência pública: "Trata-se de uma sociedade e de uma comunidade científica que se negam a reconhecer a problemática social agravada, donde segue o equívoco de acusar a vítima" (DEMO, id. ibid).

Há que se ressaltar que o processo de exclusão tende a se tornar permanente, na medida em que não se permite aos excluídos sair de tal círculo, quer por inexistência/insuficiência ou deficiência das políticas habitacionais e de inclusão, quer por seus próprios meios, o que exigiria um cenário que possibilitasse a ascensão econômica. Nesse sentido:

A tendência à concentração regional de renda é fenômeno observado universalmente [...] Uma vez iniciado este processo, sua reversão espontânea é praticamente impossível. Em um país da extensão geográfica do Brasil, é de esperar que tal processo tenda a prolongar-se extremamente[...] À

${ }^{4}$ Sobre igualdade e justiça distributiva ver RAWLS, Teoria da Justiça e DWORKIN, A Virtude Soberana: teoria e prática da igualdade. Optou-se por não se aprofundar neste referencial teórico por considerar a realidade pátria bem distinta da norte-americana. 
medida que se toma consciência da natureza desse problema no Brasil, as tensões de caráter regional - que se haviam reduzido substancialmente nos decênios anteriores, poderão voltar a apresentar-se (FURTADO, 2003, p. 248).

A obra de Aluísio de Azevedo pode parecer demasiado fantasiosa e impregnada de símbolos e valores aparentemente lacônicos e alheios à atualidade. Entretanto, mostra-se contemporânea e completamente inserida no atual conceito de sociedade pós-moderna que já não consegue ocultar, ou ao menos disfarçar o incômodo da pobreza.

As "tragédias urbanas" narradas pelo autor da obra 'O Cortiço' ultrapassam dois séculos e ainda espelham nossa realidade. A poesia de Carlos Drumond de Andrade ainda provoca o mesmo "incômodo" que a obra de Azevedo:
A suntuosa Brasília, a esquálida Ceilândia
Contemplam-se. Qual delas falará
Primeiro? Que tem a dizer ou a esconder
Uma da outra? Que mágoas, que ressentimentos
Prestes a saltar da goela coletiva
E não se exprimem? Por que Ceilândia fere
O majestoso orgulho da flórea Capital?
Por que Brasília resplandece
Ante a pobreza exposta dos casebres
De Ceilândia,
Filhos da majestade de Brasília?
E pensam-se, remiram-se em silêncio
As gêmeas criações do gênio Brasileiro (ANDRADE, 1984, p 122).

Mas o que justifica o estudo da desigualdade sob o prisma urbano? Como bem aponta Sposito (2006, p. 10), a cidade é o território-suporte para a atividade industrial, na medida em que reúne as condições necessárias para a forma de produção industrial, notadamente pela facilidade de controle produtivo das cidades enquanto centros de gestão.

Ocorre que nos países subdesenvolvidos o processo de industrialização desorganizada se apropriou das formas de produção tradicionais, causando o êxodo rural e a ocupação irregular das cidades.

Entretanto, a carência de unidades habitacionais em condições minimamente dignas é um problema que assola os centros urbanos, notadamente as cidades mais populosas, que "[...] nunca foram um espaço tão importante, nem a urbanização um processo tão expressivo e extenso a nível mundial, como a partir do capitalismo" (SPOSITO, 2006, p. 30). 
Compreender urbanização a partir do desenvolvimento industrial é procurar entender o próprio desenvolvimento do capitalismo. O modo de produção capitalista criou uma classe assalariada: trabalhadores livres da condição servil, mas desprovidos de propriedades. O grande problema é que, na visão mais cruel do sistema (o famigerado "capitalismo selvagem"), essas pessoas constituem um "peso" para o Estado.

Os dados do IBGE corroboram que a desigualdade na distribuição de renda reflete diretamente no déficit habitacional e que as desigualdades regionais requerem a adoção de estratégias distintas para o enfrentamento do problema.

Não bastasse a insuficiência de moradia em números absolutos, estudos do IBGE realizados no ano de 2013 apontam que um terço da população brasileira não possui acesso simultâneo à água tratada e energia elétrica (IBGE, 2013).

Desincumbir-se de tal "peso" pressupõe ação efetiva do Estado, quer por meio de medidas econômicas, quer por meio de políticas públicas. O problema do déficit habitacional no Brasil encontra-se intimamente ligado ao desordenado processo de urbanização e às desigualdades regionais.

\section{CONSIDERAÇÕES FINAIS}

As obras de Aluísio Azevedo, Darcy Ribeiro e Pedro Demo denotam que o passar do tempo só consolidou a situação da moradia precária. Continua a existir um contingente humano considerável que, segregado e desprovido do mínimo necessário a uma vida digna, sobretudo quanto a um teto que os abrigue, segue à margem da sociedade e mais vulnerável a problemas de saúde, educação, segurança pública entre outros.

O processo de formação das cidades aqui retratado, em breves notas, não suprime nem exclui o conhecimento de que também existem problemas habitacionais fora dos núcleos urbanos. Há carências de moradias em áreas indígenas e quilombolas, assim como em áreas rurais, cujos estudos específicos precisam detalhá-las.

A exclusão representa uma ruptura do liame social, um fator de desagregação. O rompimento dos laços sociais pode se dar por meio da perda do emprego, da ausência de moradia e seus efeitos (nas relações familiares, sobretudo) como um sistema que se retroalimenta: a exclusão desagrega, a desagregação exclui. Não porque lhes ignore a existência e sim por não lhes dar o devido reconhecimento.

Os desprovidos de moradia ou os que moram indignamente são segregados sociais. Por não se mostrar propensa a tomar parte do problema e defender a mudança desta realidade. A ausência da proteção de um teto viola o direito à vida, à intimidade, à segurança, à vida privada, entre outros. 
Viola, porém, com maior veemência, a dignidade, o íntimo, a autoestima, a consciência do ser e de seu papel na trama social. Conclui-se, portanto, que o insucesso das políticas de moradia constituem uma omissão inconstitucional, em decorrência do fato de que provocam e pioram a situação de exclusão social.

\section{REFERÊNCIAS}

ANDRADE, Carlos Drummond. Corpo. 4 ed. Record, 1984.

AZEVEDO, Aluísio. O Cortiço. 1880.

CHALHOUB, Sidney. Cidade Febril: cortiços e epidemias na corte imperial. São Paulo: Companhia das Letras, 1996.

COULANGES, Fustel de. A Cidade Antiga. São Paulo: Martin Claret, 2006.

DALCASTAGNÈ, Regina. Da Senzala ao Cortiço: história e literatura em Aluísio Azevedo e João Ubaldo Ribeiro. Revista Brasileira de História, vol. 21, $\mathrm{n}^{\circ}$ 42, p. 483-494, 2001.

DEMO, Pedro. Exclusão Social - categorias novas para realidades velhas. Revista do Programa de Pós-Graduação em Política Social da Universidade de Brasília, n.3, p. 9-55, jul-dez., 1998.

DRUCKER, Peter F. As novas realidades no governo e na política, na economia e nas empresas, na sociedade e na visão do mundo. Trad: Carlos Afonso Malferrari. São Paulo: Pioneira, 1997.

ENGELS, Frederich. Para a questão da habitação. Trad: João Pedro Gomes. Lisboa: Avante-Progresso, 1984.

FURTADO, Celso. A fantasia organizada. Rio de Janeiro: Paz e Terra, 1985.

Em busca de um novo modelo: reflexões sobre a crise contemporânea. São Paulo: Paz e Terra, 2002.

. A formação econômica do Brasil. 32. ed. São Paulo: Companhia Editora Nacional, 2003.

IBGE. Síntese de indicadores sociais: uma análise das condições de vida da população brasileira 2013. Série Estudos e Pesquisas. Informação Demográfica 
e Socioeconômica, n. 32, 2013.

NOLASCO, Loreci Gottschalk. Direito fundamental à moradia. São Paulo: Editora Pillares, 2008.

RAMOS, Demetrius dos Santos. O Direito Fundamental à Moradia Digna: do "cortiço" de Aluízio Azevedo ao direito de laje. In: HOGEMANN, Edna Raquel; ARRUDA, Érica Maia C.. (Org.). Encontro entre direito e narrativa literária. Rio de Janeiro: Lumen Juris, 2016, p. 87-119.

RIBEIRO, Darcy. As américas e a civilização: estudos de antropologia da civilização. Petrópolis: Vozes, 1988.

. O Povo Brasileiro: a formação e o sentido do Brasil. São Paulo: Companhia das Letras, 1995.

SCHWAREZ, Lilia Moritz. História da Vida Privada no Brasil: contrastes da intimidade contemporânea. Coordenação Geral da Coleção de Fernando A. Novais. São Paulo: Companhia das Letras, 1998.

SPOSITO, Maria Encarnação Beltão. Capitalismo e urbanização. São Paulo: Geografia Contexto, 2006. 